\title{
Expression and Localization of Human Oxytocin Receptor mRNA and Its Protein in Chorion and Decidua during Parturition
}

\author{
Masahiko Takemura, ${ }^{*}$ Tadashi Kimura, ${ }^{*}$ Shintaro Nomura," Yoko Makino," Tomoko Inoue," Tomoyuki Kikuchi," \\ Yasue Kubota, ${ }^{*}$ Yoshihiro Tokugawa, " Toshikatsu Nobunaga, ${ }^{*}$ Shoji Kamiura, ${ }^{*}$ Hitoshi Onoue," \\ Chihiro Azuma, * Fumitaka Saji, ${ }^{*}$ Yukihiko Kitamura, ${ }^{\star}$ and Osamu Tanizawa* \\ ${ }^{*}$ Departments of Obstetrics and Gynecology, and ${ }^{\ddagger}$ Pathology, Osaka University Medical School, Suita Osaka 565, Japan; \\ and ${ }^{\S}$ Department of Biochemistry, Rohto Pharmaceutical Co. LTD., Osaka 544, Japan
}

\begin{abstract}
Oxytocin (OT) is widely used to induce labor in the clinical setting. However, its physiological role in normal human parturition remains unclear. We demonstrated the enhanced expression of OT receptor (OTR) mRNA in chorio-decidual tissue, using the polymerase chain reaction after the reverse transcriptase reaction (RT-PCR) and Northern blot analysis. OTR gene expression in chorio-decidual tissue increased fivefold during the course of parturition. In situ hybridization of fetal membrane revealed the expression of OTR mRNA in maternally derived decidual cells. The OTR mRNA was also detected in fetally derived chorionic trophoblast cells. Immunohistochemistry, using a newly developed anti-OTR monoclonal antibody, demonstrated the distribution of OTR protein in fetal membrane. The distribution pattern of OTR protein and OTR mRNA was identical, indicating that the regulation of OTR expression occurs mainly at the transcriptional level. These results support the idea that the expression of decidual OTR regulates the initiation and amplification of labor. The implications of these findings with regard to the pathogenesis of preterm labor are also discussed. (J. Clin. Invest. 1994. 93:23192323.) Key words: oxytocin receptor - fetal membrane · in situ hybridization $\cdot$ labor $\cdot$ monoclonal antibody
\end{abstract}

\section{Introduction}

Oxytocin (OT), ${ }^{1}$ one of the strongest uterotonins (uterine contractants), is used for the induction of labor in the clinical setting. Although it is thought to be crucial in the initiation of parturition, the mechanism whereby it does so is poorly understood. Uterine sensitivity to OT varies greatly and appropriate timing of its use is important for successful induction. In some subjects, a pharmacological dose of OT does not induce labor, while in others only a drop of OT induces hypertonic uterine contractions. The concentration of OT in maternal plasma during spontaneous parturition does not change significantly before and during parturition $(1,2)$.

Address correspondence to Tadashi Kimura, M.D., Ph.D., Department of Obstetrics and Gynecology, Osaka University Medical School, 2-2 Yamadaoka Suita, Osaka 565, Japan.

Received for publication 29 November 1993 and in revised form 9 February 1994

1. Abbreviation used in this paper: OT, oxytocin. OTR, oxytocin receptor; RT-PCR, PCR after reverse transcriptase reaction.

J. Clin. Invest.

(C) The American Society for Clinical Investigation, Inc.

$0021-9738 / 94 / 06 / 2319 / 05 \quad \$ 2.00$

Volume 93, June 1994, 2319-2323
We have previously cloned a cDNA for human OT receptor (OTR), and we showed that the expression of OTR mRNA in the human myometrium was markedly increased at parturition (3); this indicated that the sensitivity of the myometrium to OT regulated the action of this agent, and confirmed the results of early studies with binding assay $(4,5)$ at transcriptional level. However, this finding does not explain the interrelationship between OT and other uterine contractants at parturition. OT infusion has been shown to raise plasma prostaglandin (PG) F $2_{\alpha}$ level only when the induction of labor succeeded (6), and OT stimulation in vitro induced the production of $\mathrm{PGF}_{2 \alpha}$ in decidual cells (7). $\mathrm{PGF}_{2 \alpha}$ is also a potent uterotonin. These studies suggest that OT not only directly contracts the myometrium, but that it also regulates myometrial contraction through stimulating the production of other uterotonins at the feto-maternal interface. This interface, which consists of the amnion, chorion laeve, and decidua, is ideally situated to regulate the signals from the fetus and/or outside the uterus to the myometrium at parturition.

In this study, we investigated the expression of the OTR gene at the feto-maternal interface during parturition, using the polymerase chain reaction after the reverse transcriptase reaction (RT-PCR) and Northern blot hybridization. We also determined the cellular localization of OTR in these tissues at the transcriptional and translational levels, using in situ hybridization and immunohistochemistry with a newly developed monoclonal antibody. Through these experiments we attempted to demonstrate the role of OTR at the feto-maternal interface during parturition.

\section{Methods}

Tissue preparation. Chorio-decidual membranes were obtained from subjects who underwent either vaginal or cesarean delivery, the indications for cesarean delivery being previous cesarean section, fetal anomaly, and dystocia (Table I). Informed consent was obtained from all subjects. The tissue specimens for RNA preparation were immediately frozen in liquid nitrogen after separation from the amniotic membrane, and stored at $-80^{\circ} \mathrm{C}$. Tissues to be subjected to in situ hybridization and anti-cytokeratin immunohistochemistry were fixed with freshly prepared $4 \%$ paraformaldehyde in $0.1 \mathrm{M}$ sodium phosphate buffer (PB; $\mathrm{pH} 7.4)$ for $24 \mathrm{~h}$ at $4^{\circ} \mathrm{C}$. The fixed specimens were embedded in paraffin wax after dehydration by the conventional method. Tissues to be subjected to immunohistochemistry with anti-OTR antibody were immediately embedded in OCT (Miles Inc., Elkhart, IN), frozen in liquid nitrogen, and stored at $-80^{\circ} \mathrm{C}$ until use.

Placental tissues were obtained after a vaginal delivery. Tissue samples were taken from the mid-part of the placenta to avoid contamination by extravillus trophoblasts or decidual tissue. These specimens were also frozen in liquid nitrogen after vigorous washing with saline, and were stored at $-80^{\circ} \mathrm{C}$ until RNA extraction.

$R N A$ extraction and $R T-P C R$. Oligonucleotide primers were designed to amplify a 391-bp (1215-1602) fragment of oxytocin receptor cDNA, 
Table I. Clinical Data of the Patients from Whom Specimens Were Obtained for Northern Blot Analysis

\begin{tabular}{ccclcc}
\hline $\begin{array}{c}\text { Case } \\
\text { No. }\end{array}$ & $\begin{array}{c}\text { Gestation } \\
\text { week }\end{array}$ & $\begin{array}{c}\text { Mode of } \\
\text { delivery }\end{array}$ & Indication for C/S & Labor & $\begin{array}{c}\text { Cervical } \\
\text { dilatation }\end{array}$ \\
\hline & & & & & $\mathrm{cm}$ \\
1 & 37 & $\mathrm{C} / \mathrm{S}$ & Previous C/S & - & 2 \\
2 & 38 & $\mathrm{C} / \mathrm{S}$ & Previous C/S & - & 3 \\
3 & 37 & $\mathrm{C} / \mathrm{S}$ & Previous C/S & - & 1.5 \\
4 & 37 & $\mathrm{C} / \mathrm{S}$ & Previous C/S & $\pm^{*}$ & 3 \\
5 & 37 & $\mathrm{C} / \mathrm{S}$ & Previous C/S & $\pm^{*}$ & 3 \\
6 & 38 & $\mathrm{C} / \mathrm{S}$ & Previous C/S & + & 5 \\
7 & 36 & $\mathrm{C} / \mathrm{S}$ & Fetal anomaly & + & 5 \\
8 & 37 & $\mathrm{C} / \mathrm{S}$ & Dystocia & ++ & 7 \\
9 & 39 & Vaginal & & ++ & 10 \\
& & & & & \\
\hline
\end{tabular}

* Braxton Hicks contraction; C/S, cesarean section.

and a 741-bp (384-1124) fragment of $\beta$-actin cDNA (8). The sequences of the primers were; OTR-F, 5'CCTTCATCGTGTGCTGGACG3' (oxytocin receptor 5'); OTR-R, 5'CTAGGAGCAGAGCACTTATG3' (oxytocin receptor 3); BETA-F, 5'AACCGCGAGAAGATGACCCAG3' ( $\beta$-actin 5); and BETA-R, 5'CTCCTGCTTGCTGATCCACAT3' ( $\beta$-actin 3$)$. Since our investigation of OTR genomic DNA sequence revealed that there is a 12-kbp intron at the 1,289th base of the OTR cDNA (manuscript in preparation), the primers theoretically do not amplify any genomic DNA fragment. We confirmed it by PCR of genomic DNA (data not shown).

Total RNA from the tissue specimens was prepared by the guanidium cesium chloride method (9). Each RNA sample ( $1 \mu \mathrm{g})$ was reverse transcribed in $20 \mu$ l of reaction mixture containing $200 \mathrm{U}$ of Moloney murine leukemia virus reverse transcriptase (GIBCO BRL, Gaithersburg, MD) and $50 \mathrm{pmol}$ antisense primers for oxytocin receptor (OTR$R$ ) and $\beta$-actin (BETA-R). Each reaction product was then amplified by PCR in $80 \mu$ l of PCR buffer containing $1 \mathrm{U}$ of Taq DNA polymerase (Boehringer Mannheim GmbH Biochemica, Mannheim, Germany) and 12.5 pmol each of the specific primer pair for oxytocin receptor (OTR-F and OTR-R). The reaction was carried out for 25 and 30 cycles using a thermocycler (Perkin-Elmer, Cetus Corp., Emeryville, CA). The reverse transcribed products were also amplified by PCR, using 12.5 pmol each of a specific primer pair for $\beta$-actin (BETA-F and BETA-R). This reaction was carried out for 15 cycles. A $15-\mu 1$ aliquot of each product was electrophoresed on agarose gel and stained with ethidium bromide.

Northern blot analysis. Poly(A) ${ }^{+}$RNA was isolated from total RNA by using oligo(dT)-latex beads (Oligotex-dT30; Takara, Kyoto, Japan); $1 \mu \mathrm{g}$ of the poly $(\mathrm{A})^{+}$RNA was then electrophoresed on a $1 \%$ agarose2.2 $\mathrm{M}$ formaldehyde gel, and blotted onto nylon membrane filters (Geenscreen; NEN DuPont, Boston, MA). The filters were hybridized at $43^{\circ} \mathrm{C}$ for $16 \mathrm{~h}$ with a $0.8-\mathrm{kb}$ BamHI-PstI fragment of the OTR cDNA, which was labeled with ${ }^{32} \mathrm{P}$ by the random primer method. The filters were washed for $1 \mathrm{~h}$ at $50^{\circ} \mathrm{C}$ in $0.2 \times \mathrm{SSC}$ buffer, containing $0.1 \%$ SDS, and were exposed to Kodak XAR film (Eastman Kodak Co., Rochester, NY) for $24 \mathrm{~h}$ with two intensifying screens at $-70^{\circ} \mathrm{C}$. The filters were also exposed to an imaging plate (Fuji Photo Film Co., Tokyo, Japan) for one hour, from which quantitative analysis was performed with imaging plate scanners (BAS2000; Fuji Photo Film Co.).

After analysis, the filters were dehybridized and rehybridized with a ${ }^{32}$ P-labeled $\beta$-actin cDNA fragment (Wako Pure Chemical Industries, Osaka, Japan) as an internal control.

In situ hybridization histochemistry. Digoxigenin-labeled single strand RNA probes were prepared, using a DIG RNA Labeling Kit (Boehringer Mannheim) according to the manufacturer's instructions. For the generation of human OTR-specific probes, three fragments of oxytocin receptor cDNA were subcloned into Bluescript I plasmid; a BglII- and DraI-digested 255-bp (3035-3289) fragment (OTR255), a
PstI- and ApaI-digested 388-bp (686-1074) fragment (OTR388), and a Pstl-digested 484-bp (1079-1562) fragment (OTR484). The plasmids were linearized with the appropriate enzymes, and transcribed with T3 or T7 RNA polymerase to generate antisense or sense cRNA probes.

In situ hybridization was carried out as described previously (10). The hybridized digoxigenin-labeled probe was detected with a Nucleic Acid Detection Kit (Boehringer Mannheim), used according to the manufacturer's instructions. Controls consisted of: $(a)$ hybridization with the sense (mRNA) probe, (b) RNase A treatment $(20 \mu \mathrm{g} / \mathrm{ml})$ before hybridization for $30 \mathrm{~min}$ at $37^{\circ} \mathrm{C}$, and $(c)$ use of neither antisense RNA probe nor antidigoxigenin antibody. No signals were obtained in these three control experiments.

Production of anti-human OTR monoclonal antibody. A 21-amino acid-long peptide comprising the $\mathrm{NH}_{2}$-terminal region of OTR was custom synthesized. The sequence of the peptide was PPGAEGNRTAGPPRRNEALAR (from the 20th amino acid to the 40th). The synthetic peptide was coupled to keyhole lipid hemocyanin (Calbiochem-Novabiochem Co., San Diego, CA) and to albumin, chicken egg grade V (Ovalbumin; Sigma Chemical Co., St. Louis, MO) as described by Hashida et al. (11), and BALB/C mice were immunized with the conjugate. The conjugate with $0.1 \mathrm{ml}$ of Freund's complete adjuvant (Difco Laboratories Inc., Detroit, MI) was injected subcutaneously 50 $\mu \mathrm{g} /$ mouse for the first immunization; for the second, carried out $10 \mathrm{~d}$ after the first, $5 \mu \mathrm{g} /$ mouse of the conjugate was injected intraperitoneally immunization. $3 \mathrm{~d}$ after the second immunization, spleen cells were collected and fused with myeloma cell P3X63Ag8U1 (American Type Culture Collection, Rockville, MD). The obtained hybridomas were cloned by the limiting dilution method. The antibody titer was evaluated by determining binding to the peptide-OVA conjugate. The antibody, isolated and purified from the culture supernatant by salting out with ammonium sulfate, was designated $2 \mathrm{~F} 8$.

Immunohistochemistry. The frozen embedded tissues, which were obtained after normal delivery, were sectioned and fixed with acetone for $10 \mathrm{~min}$ on glass slides. These sections were then treated for $30 \mathrm{~min}$ with methanol containing $0.3 \%$ hydrogen peroxide to eliminate intrinsic peroxidase activity. Immunohistological staining was performed using the Vectastain $\mathrm{ABC}$ Kit (Vector Laboratories Inc., Burlingame, $\mathrm{CA}$ ) according to the manufacturer's instructions with $0.45 \mathrm{~mol} / \mathrm{l} \mathrm{so-}$ diumchloride in the buffer for primary antibody. The anti-OTR monoclonal antibody $2 \mathrm{~F} 8(10 \mu \mathrm{g} / \mathrm{ml})$, was used as the primary antibody. The incubation time for the primary and secondary antibody were $30 \mathrm{~min}$ each at room temperature. A mixture of equal amounts of $0.02 \%$ hydrogen peroxide and $0.1 \%$ DAB solution was used as the color substrate solution. The specificity of the antibody was comfirmed by $(a)$ using normal mouse IgM fraction as the primary antibody, and $(b)$ addition of the $5 \mu \mathrm{g} / \mathrm{ml}$ synthetic peptide to neutralize the primary antibody.

The localization of trophoblast in the same specimens used in the in situ hybridization was shown by immunohistological staining using anti-cytokeratin monoclonal antibody $(10 \mu \mathrm{g} / \mathrm{ml})$ (Shandon Inc. Pittsburgh, PA) as the primary antibody.

\section{Results}

$R T-P C R$. To determine the expression of OTR mRNA in chorion-decidua, we examined, by RT-PCR, the tissues from three subjects before the onset of labor (Fig. 1, lanes 1-3) and three after normal parturition (Fig. 1, lanes 4-6). 25 cycles of PCR amplification after the reverse transcriptase reaction yielded products derived from OTR mRNA only in the tissues of the three subjects examined after parturition (Fig. $1 A$ ). On 30 cycles of PCR, the amplified product of OTR mRNA was. detected in the tissues of the three subjects before the onset of labor as well as in those after parturition, indicating that the expression level of OTR mRNA may increase during parturition. However, no detectable product was obtained in two samples of placental trophoblasts (Fig. $1 \mathrm{~B}$, lanes 7, 8). 15 PCR 


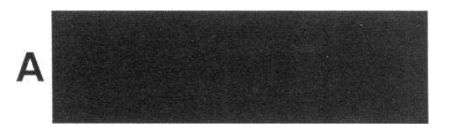

B

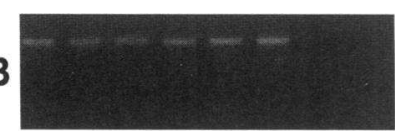

C

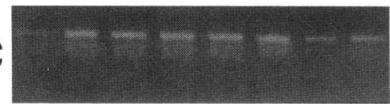

Figure 1. Detection of OTR mRNA in human tissues at parturition by RT-PCR. Total RNA ( $1 \mu \mathrm{g})$ from the choriondecidua before the onset of labor $(1,2,3)$, chorion-decidua after normal parturition $(4,5$, 6 ), and placental trophoblast after normal parturition $(7,8)$ were reverse transcribed with OTR and $\beta$-actin primers, then PCR amplified with the OTR primers for 25 and 30 cycles $(A$ and $B$, respectively) or with $\beta$-actin primers for 15 cycles $(C)$. The amplified products were directly stained with ethidium bromide on the gel.

cycles with a $\beta$-actin primer pair demonstrated that comparable amounts of RNA were used for the reaction (Fig. $1 C$ ).

Estimation of OTR MRNA expression in chorion-decidua by Northern blot analysis. To quantify OTR mRNA expression in the chorion-decidua during parturition, $\operatorname{poly}(\mathrm{A})^{+} \mathrm{RNA}$ was extracted from the chorion-decidua at various stages of parturition (Table I), and was hybridized with the OTR cDNA probe. The stage of parturition was evaluated by the conditions of uterine contraction and the dilatation of the uterine cervix. The quantification was carried out by comparing OTR mRNA expression with the expression of $\beta$-actin mRNA as an internal control (Fig. 2). The relative amount of OTR mRNA was determined by quantitative analysis, using an imaging plate analyzer. Small amounts of OTR mRNA were detected in the three chorion-decidua specimens taken prior to the onset of labor (Fig. 2, lanes 1-3). OTR mRNA increased dramatically with the onset of labor, showing good correlation with cervical dilatation, and reached a peak at the completion of parturition (Fig. 2, lanes 4-9). The intensity of the signal was approximately five times that before the onset of labor.

Localization of OTR $m R N A$. In situ hybridization was performed to determine the localization of OTR mRNA in the

$\begin{array}{lllllllll}1 & 2 & 3 & 4 & 5 & 6 & 7 & 8 & 9\end{array}$

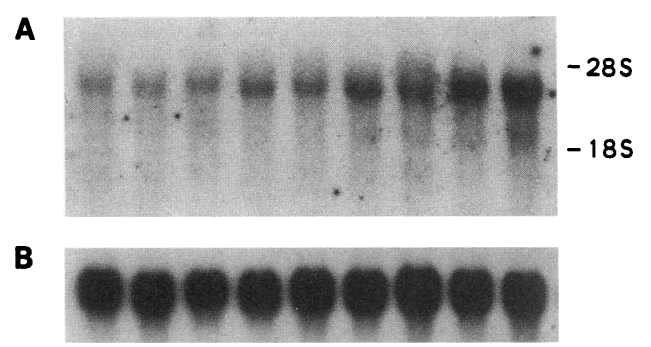

$\begin{array}{lllllllllll}\text { C } & 1.1 & 1.0 & 1.1 & 1.5 & 1.5 & 2.4 & 2.2 & 3.5 & 5.2\end{array}$

Figure 2. Northern blot analysis of OTR mRNA in chorion-decidua during parturition. Poly(A) ${ }^{+}$RNA $(1 \mu \mathrm{g})$ from chorion-decidua at various stages of parturition (Table I) were electrophoresed and transferred to a nylon membrane filter, as described in Methods. The lane numbers correspond to the case numbers in Table $I$. The filters, hybridized with a ${ }^{32} \mathrm{P}$-labeled 0.8-kb BamHI-PstI fragment of OTR cDNA $(A)$, and rehybridized with a $\beta$-actin cDNA fragment $(B)$, were exposed for $24 \mathrm{~h}$. The expression of OTR mRNA was quantified by imaging plate scanner, and standardized by the expression of $\beta$-actin. The relative amount of OTR mRNA was indicated $(C)$. One arbitarary unit is defined as the level of OTR mRNA in lane 2. chorion and the decidua. The sections of fetal membrane and decidua were hybridized with digoxigenin labeled cRNA probes. In sections taken from subjects in labor, hybridized signals were detected in the chorion laeve (Fig. $3 \mathrm{~A}$ ), the vascular rich decidual layer (Fig. $3 C$ ), and in large cobblestone-like decidual cells adjacent to the myometrium (Fig. $3 E$ ). Faint signals were observed in sections taken before the onset of labor (data not shown).

Adjacent sections were stained with anti-cytokeratin antibody, a trophoblast marker. Cytokeratin-positive chorionic trophoblasts also showed positive hybridization for OTR mRNA (Fig. 3, $G$ and $H$ ), indicating that the fetally derived chorionic trophoblasts, as well as the maternally derived decidual cells, expressed OTR mRNA.

Localization of OTR protein. To examine the localization of OTR at the translational level, frozen sections of fetal membrane were stained with the newly developed anti-OTR monoclonal antibody, 2F8. Reactions were observed in cells both in the chorion laeve and the decidual layer (Fig. 4). The distribution pattern of OTR protein was consistent with that of OTR mRNA obtained by in situ hybridization.

\section{Discussion}

In this study, we determined the spatial and temporal expression of OTR mRNA and protein during parturition. By RTPCR and Northern hybridization, we showed that the expression level of OTR mRNA in chorion-decidua was increased up to fivefold during the course of parturition. Some previous studies, in which a binding assay using labeled OT was used $(5,12)$, suggested that the decidual binding sites of OT were increased at the end of pregnancy; however, whether this was due to an increase in the number of OTR molecules or to the expression of some other OT binding protein was not elucidated. Our results, measuring transcripts level, are in agreement with these earlier binding assays. We have indicated that upregulation of OTR concentrations seen at parturition is primarily regulated at the transcriptional level.

The in situ hybridization, together with anti-cytokeratin antibody immunohistochemistry, demonstrated OTR mRNA not only in decidual cells but also in the trophoblasts of the chorion laeve, while the trophoblasts in the placenta expressed no OTR mRNA (Fig. $1 B$, lanes 7 and 8 ), suggesting differences between the trophoblasts in the chorion laeve, and these in the placenta. The expression of OTR mRNA and protein in the amnion, the other fetally derived tissue at the feto-maternal interface, seems much lower than that of trophoblasts in the chorion laeve. In the previous studies, some investigators demonstrated the plenty amount of OT binding site in the amnion $(13,14)$. However, our results are reproducible, and A.-R. Fuchs also demonstrated only trace amount of OTR in the human amnion, using a binding assay (personal communication). We are now planning to quantitate the amount of OTR in the human amnion at transcriptional and translational level. In any case, the fetally derived chorionic trophoblasts and maternally derived decidual cells both participate in the regulation of human parturition through the OT function.

The in situ hybridization experiments also suggested the possibility that decidual cells lying next to the myometrium expressed higher OTR mRNA levels than did cells lying closer to the chorion. Thus, the highest expression of OTR may occur 

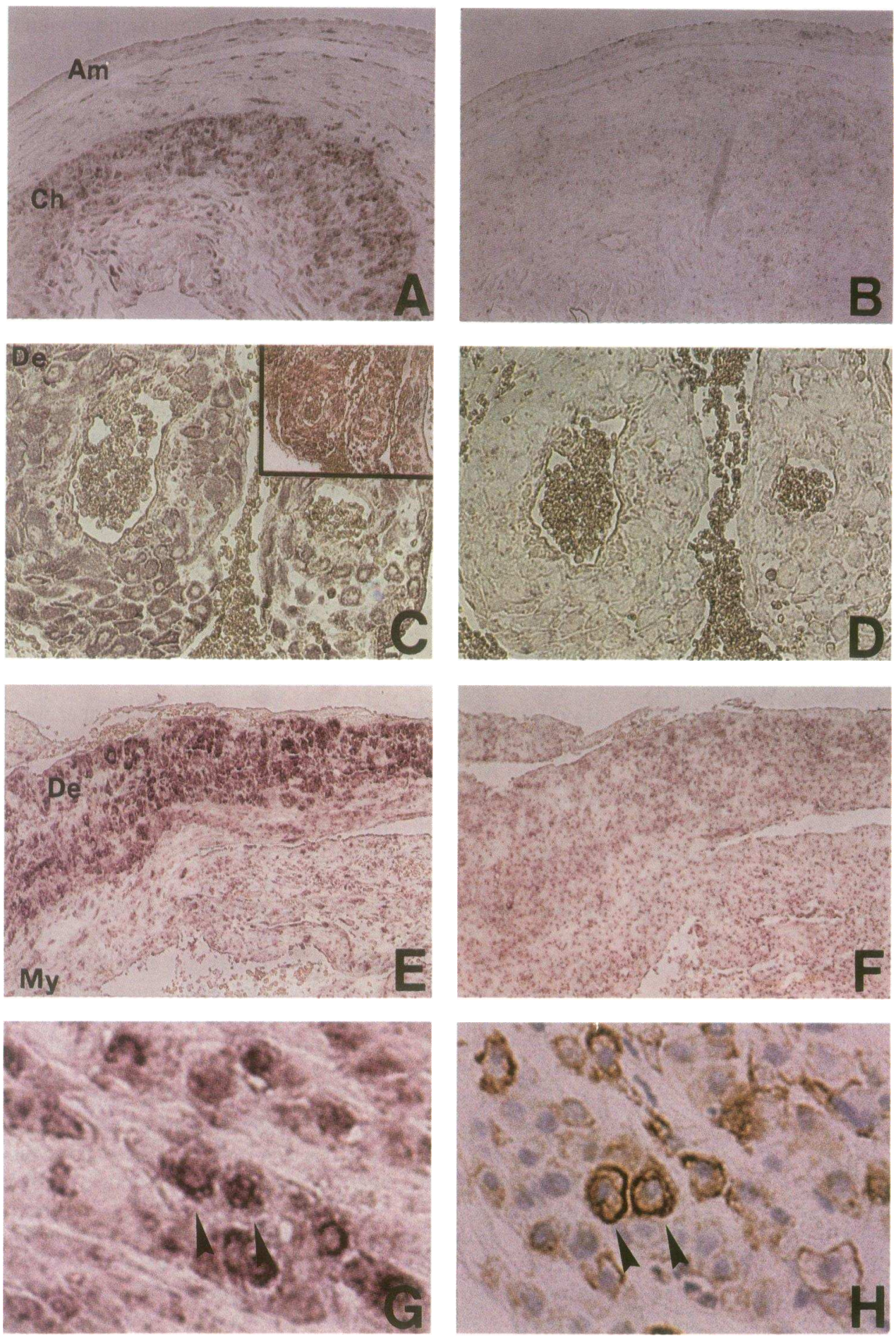

Figure 3. In situ hybridization of OTR in chorion-decidua at parturition. Sections of fetal membrane $(A-D)$ and decidual tissue remaining to inside of the uterus $(E$ and $F$ ) were hybridized with antisense $(A, C$, and $E)$ or sense $(B, D$, and $F) \mathrm{cRNA}$ probes for oxytocin receptor. At the fetal side of the membrane, amnion and chorion laeve is divided by fibrous tissue $(A$ and $B)$. At the maternal side of the membrane, chorion laeve continues to vascular rich decidua without clear boundary ( $C$ and $D$ ). Cells in the chorion laeve and the decidual layer were markedly hybridized with CRNA probes for oxytocin receptor $(A, C$, and $E)$. Sections of chorion laeve after normal parturition were hybridized with cRNA probes for oxytocin receptor $(G)$, and immunostained with anti-cytokeratin antibody $(H)$. Arrowheads show cytokeratin-positive chorionic trophoblast expression of OTR mRNA. The experiment was performed for five cases of fetal membrane obtained after normal delivery (including case 10 of Table I, and the cases for lanes 4,5 , and 6 of Fig. 1), and for two cases of decidual tissue on the myometrial side. $A m$, amnion; $C h$, chorion laeve; $D e$, decidua; $M y$, myometrium. $(A$ and $B) \times 200 ;(C$ and $D) \times 300 ;(E$ and $F) \times 220 ;(G$ and $H) \times 800$. in the region immediately adjacent to the myometrium. It has recently been demonstrated that OT mRNA was also expressed in decidua and chorion $(15,16)$, and the expression in human tissue was strongest at the decidual cells next to the myometrium (16). Namely, the localization of OTR and OT mRNA may overlap, suggesting that the local secretion of OT and the myometrial contractions induced by OT are regulated by autocrine and paracrine mechanisms.

Little is known about the factors that regulate the gene expression of OTR. The inductive effects of estrogen and the inhibitory effects of progesterone on OTR expression in the human pregnant uterus are known, but controversial $(17,18)$.
Several cytokines have been shown to be involved in preterm labor induced by local infection (19-21). Of interest in this regard, we recently analyzed the structure of the promoter region of the human OTR gene, and found several consensus sequences which have been reported to be affected by cytokines (unpublished data). Several studies also suggest an interrelationship between OT and $\mathrm{PGF}_{2 \alpha}(22-25) . \mathrm{PGF}_{2 \alpha}$ is a well known uterotonin widely used to induce labor as well as OT. It is reported that this $P G$ is produced in decidua by the action of OT $(4,6)$. This means PGF $_{2 \alpha}$ is situated at the downstream of OTR in the signal mechanisms of labor.

Taken together, our findings strongly support the hypothe- 


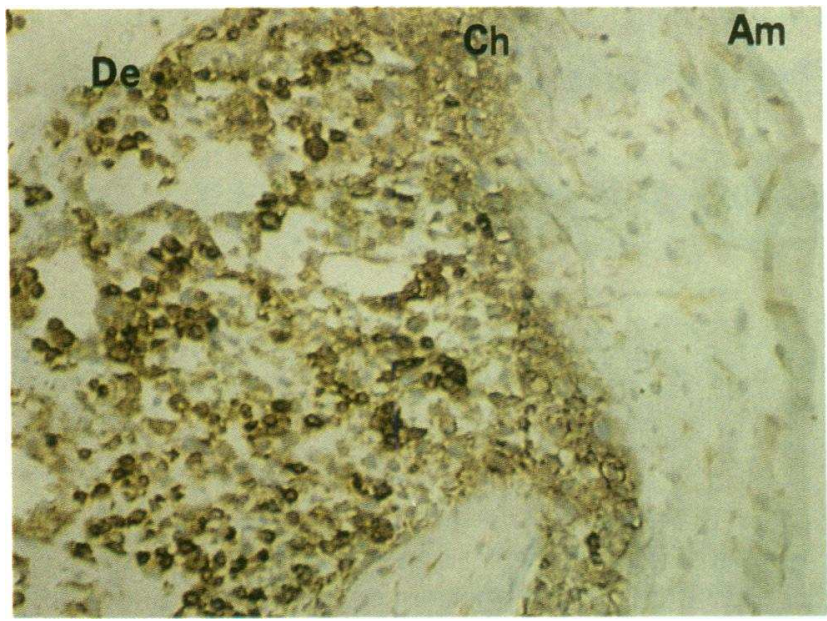

Figure 4. Immunohistochemistry of fetal membrane with anti-OTR antibody. Fresh frozen sections of fetal membranes were immunostained with the anti-OTR monoclonal antibody 2F8. Cells in the chorion laeve and the decidual layer were positively stained. The experiment was performed for three cases of fetal membrane obtained after normal delivery. $\mathrm{Am}$, amnion; $\mathrm{Ch}$, chorionic laeve; $\mathrm{De}$, decidua. $(\times 250)$

sis that OTR expression is a limiting factor of parturition, which was proposed in the previous reports $(4,5)$. They also explain how OT may play a pivotal role in the onset of labor in the absence of significant changes in maternal plasma concentration. Further investigation of the regulatory mechanism of OTR gene expression is essential to elucidate the mechanisms responsible for human parturition. To this end, we are now investigating the biological significance of the upstream sequences in our laboratory.

\section{Acknowledgments}

This work was supported in part by a Grant-in-Aid from the Ministry of Education, Science and Culture of Japan (04454417, 05454450, 04671002, 05454449, and 04671003).

\section{References}

1. Leake, R. D., R. E. Weitzman, T. H. Glantz, and D. H. Fisher. 1981. Plasma oxytocin concentrations in men, nonpregnant women and pregnant women before and during spontaneous labor. J. Clin. Endocrinol. \& Metab. 53: 730-733.

2. Dawood, M. Y., K. Yeidorkala, D. Trevedi, and F. Fuchs. 1979. Oxytocin in maternal circulation and amniotic fluid during pregnancy. J. Clin. Endocrinol. \& Metab. 49: 429-434.

3. Kimura, T., O. Tanizawa, K. Mori, M. Brownstein, and H. Okayama. 1992. Structure and expression of a human oxytocin receptor. Nature (Lond.). 356:526-529.

4. Soloff, M. S., M. Alexandrova, and M. J. Fernstrom. 1979. Oxytocin receptors: Triggers for parturition and lactation? Science (Wash. DC). 204:1313-1314.
5. Fuchs, A. R., F. Fuchs, P. Husslein, and M. S. Solof. 1984. Oxytocin receptors in the human uterus during pregnancy and parturition. Am. J. Obstet. Gynecol. 150: 734-741.

6. Husslein, P., A. -R. Fuchs, and F. Fuchs. 1981. Oxytocin and the initiation of human parturition. I. Porstaglandin release during induction of labor by oxytocin. Am. J. Obstet. Gynecol. 141: 688-693.

7. Fuchs, A.-R., P. Husslein, and F. Fuchs. 1981. Oxytocin and the intiation of human parturition. II. Stimulation of prostaglandin production in human decidua by oxytocin. Am. J. Obstet. Gynecol. 141: 694-698.

8. Ponte, P., S. Y. Ng, J. Engel, P. Gunning, and L. Kedes. 1984. Evolutionary conservation in the untranslated regions of actin mRNAs: DNA sequence of a human beta-actin cDNA. Nucleic Acids Res. 12: 1687-1696.

9. Kimura, T., C. Azuma, F. Saji, M. Takemura, Y. Tokugawa, M. Miki, M. Ono, K. Mori, and O. Tanizawa. 1992. Estimation by an electrophysiological method of the expression of oxytocin receptor mRNA in human myometrium during pregnancy. J. Steroid. Biochem. Mol. Biol. 42: 253-258.

10. Takemura, M., S. Nomura, T. Kimura, T. Inoue, H. Onoue, C. Azuma, F. Saji, Y. Kitamura, and O. Tanizawa. 1993. Expression and localization of oxyto cin receptor gene in human endometrium in relation to the menstrual cycle. Endocrinology. 132: 1830-1835.

11. Hashida, S., I. Masayoshi, S. Inoue, K. -H. Ruan, and E. Ishikawa. 1984. More useful maleimide compounds for the conjugation of Fab to Horseradish peroxidase through thiol groups in the hinge. J. Appl. Biochem. 6: 56-63.

12. Hinko, A., and M. S. Soloff. 1992. Characterization of oxytocin receptors in rabbit amnion involved in the production of prostaglandin E2. Endocrinology. 130: $3547-3553$

13. Fukai, H., D. K., H. Sakamoto, H. Kodaira, F. Uchida, and S. Takagi. 1984. Study of oxytocin Receptor: II. Oxytocin and Prostaglandin F2alpha receptors in human myometria and amnion-decidua complex during pregnancy and labor. Endocrinol. Japon. 31: 565-570.

14. Benedetto, M. T., F. De Cicco, A. Rossiello, A. L. Nicosia, G. Lupi, and S. Dell'Acqua. 1990. Oxytocin receptor in human fetal membranes at term and during labor. J. Steroid. Biochem. 35: 205-208.

15. Lefebvre, D. L., A. Giaid, H. Bennett, R. Lariviere, and H. H. Zingg. 1992 Oxytocin gene expression in rat uterus. Science (Wash. DC). 256: 1553-1555.

16. Chibbar, R., F. D. Miller, and B. F. Mitchell. 1993. Synthesis of oxytocin in amnion, chorion, and decidua may influence the timing of human parturition. J. Clin. Invest. 91: 185-192.

17. Soloff, M. S., M. A. Fernstroem, S. Periyasamy, S. Soloff, S. Baldwin, and M. Wieder. 1983. Regulation of oxytocin receptor concentration in rat uterine explants by estrogen and progesterone. Can. J. Biochem. Cell Biol. 61: 625-630.

18. Vallet, J. L., G. E. Lamming, and M. Batten. 1990. Control of endometrial oxytocin receptor and uterine response to oxytocin by progesterone and oestradiol in the ewe. J. Reprod. Fert. 90: 625-634.

19. Romero, R., and M. Mazor. 1988. Infection and preterm labor. Clin. Obstet. Gynecol. 31: 553-584.

20. Romero, R., M. Sirtoi, E. Oyarzun, C. Avila, M. Mazor, R. Callahan, V. Sabo, A. P. Athanassiadis, and J. C. Hobbins. 1989. Infection and labor. V. Prevalence, microbiology, and clinical significance of intraamniotic infections in women with preterm labor and intact membranes. Am. J. Obstet. Gynecol. 161: 817-824.

21. Taniguchi, T., N. Matsuzaki, T. Kameda, K. Shimoya, T. Jo, F. Saji, and O. Tanizawa. 1991. The enhanced production of placental interleukin-1 during labor and intrauterine infection. Am. J. Obstet. Gynecol. 165: 131-137.

22. Skinner, K. A., and J. R. G. Challis. 1985. Changes in the synthesis and metabolism of prostaglandins by human fetal membranes and decidua at labor. Am. J. Obstet. Gynecol. 151: 519-523.

23. Olson, D. M., K. Skinner, and J. R. G. Challis. 1983. Estradiol-17beta and 1-hydroxyestradiol-17beta induced differential production of prostaglandins by cells dispersed from human intrauterine tissues at parturition. Prostaglandins. 25: 639-651.

24. Chen, W. Y. 1987. Enhanced prostaglandin synthesis in the parturient rat uterus and its effects on myometrial oxytocin receptor concentrations. Prostaglandins. 34: 889-902.

25. Moore, J. J., R. M. Moore, and D. Vanderkooy. 1991. Protein kinase-C activation is required for oxytocin induced prostaglandin production in human amnion cells. J. Clin. Endocrinol. \& Metab. 72: 1073-1080. 